\title{
The effect of intravenous Aminoplex 5 on serum gastrin and gastric secretion
}

\author{
K. Chatamra \\ F.R.C.S. \\ H. W. S. PigotT \\ F.R.C.S.
}

J. I. MacNaughton

B.Sc.

C. WASTELL

M.S., F.R.C.S.

Surgical Unit, The Gordon Hospital, Westminster Teaching Group

\begin{abstract}
Summary
Aminoplex 5 (Geistlich Ltd), which contains the essential amino-acids in laevo form plus sorbitol and $5 \%$ ethanol, may be infused intravenously for at least one hour in patients who are undergoing prolonged nasogastric suction without fear of great gastric hypersecretion of acid.
\end{abstract}

\section{Introduction}

The reason for this investigation was the speculation that patients with long continued nasogastric suction and therefore an empty stomach might be liable to gastric or duodenal erosion if given a gastric mucosal stimulant. Therefore, the effect of intravenous Aminoplex 5 on gastric secretion in ten young, fasting, healthy, male volunteers was studied.

\section{Material and methods}

Ten male volunteers without a history of abnormal gastric function, fasted for $10 \mathrm{hr}$ overnight. A nasogastric tube was then passed and the resting juice aspirated. A $200 \mathrm{ml}$ wash of water was instilled down the tube and immediately aspirated to check that the stomach was free of food debris and the tube was in the correct position. Gastric juice was then collected for a period of $3 \mathrm{hr}$ by continuous suction at a negative pressure of $50 \mathrm{mmHg}$, interrupted approximately every $15 \mathrm{~min}$ for the injection of $20 \mathrm{ml}$ of air down the tube to clear it of mucus.

In the first hour normal saline was administered intravenously, via a small cannula inserted into an arm vein, at a rate of $50 \mathrm{drops} / \mathrm{min}$ (equivalent to 1 litre/6 hr).

Correspondence: Mr K. Chatamra, Surgical Registrar, The Gordon Hospital, Vauxhall Bridge Road, London SW1.
In the second hour the intravenous infusion was changed to Aminoplex 5 at the same rate and for the third hour it was again normal saline at the same rate.

Aminoplex 5 contains the following laevo form amino-acids:

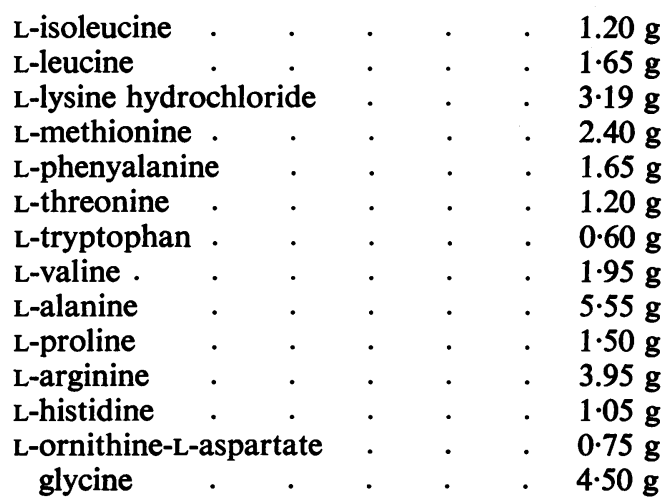

together with nicotinamide $0.05 \mathrm{~g}$, L-malic acid $2.01 \mathrm{~g}$, vitamin $B_{6} 0.03 \mathrm{~g}$, sorbitol $125 \mathrm{~g}$, ethanol $50 \mathrm{~g}$, sodium $35 \mathrm{mEq}$, potassium $15 \mathrm{mEq}$ and chloride 62 $\mathrm{mEq}$ in 1 litre of solution.

The gastric juice was collected as 12 aliquots of $15 \mathrm{~min}$ each. The acid content was measured by means of titration against $\mathrm{N} / 10 \mathrm{NaOH}$ to $\mathrm{pH} 7$ using a pH meter.

Venous blood was taken at the beginning of the test and at hourly intervals thereafter in the first eight subjects, for gastrin assay. The assay used was a modification by Pigott (1973), of the radio immunoassay described by Hansky and Cain (1969). Also the venous blood of two subjects was taken for blood glucose estimation. 
Results

\section{Acid secretion}

The mean output of acid for all subjects for each 15-min period is shown in Fig. 1.

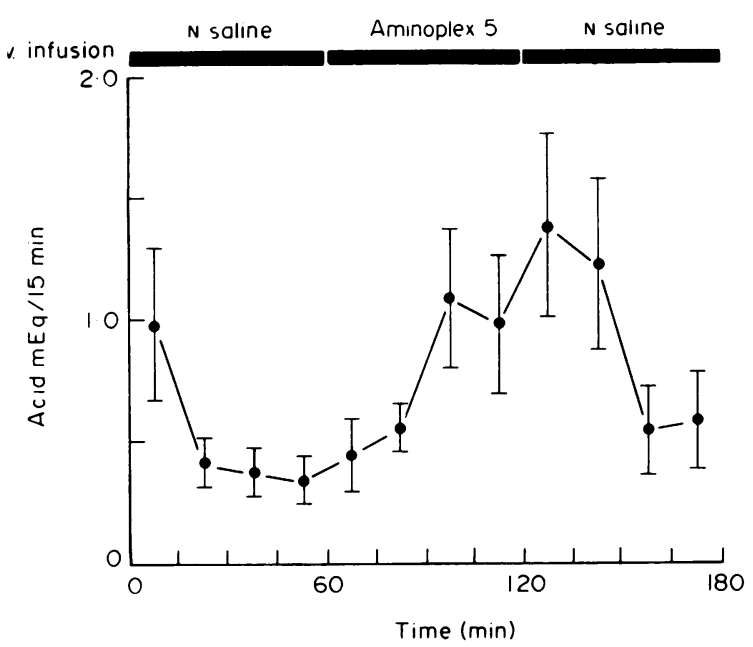

Fig. 1. The mean acid secretion (s.e. mean) in $\mathrm{mEq} / 15$ min of ten subjects.

The first 15 min during saline infusion yielded an average secretion of $0.98 \mathrm{mEq} \mathrm{H} \mathrm{H}^{+}$which was higher than the subsequent three 15-min aliquots which were $0.41,0.37$ and $0.34 \mathrm{mEq} \mathrm{H}^{+}$, respectively.

Following the substitution of Aminoplex 5 for normal saline the mean secretion for each $15 \mathrm{~min}$ was $0.44,0.55,1.08$ and $0.98 \mathrm{mEq} \mathrm{H}^{+}$respectively. An analysis of variance indicates that acid secretion during the time the Aminoplex was being infused was significantly greater than that occurring in the first hour, the expected mean square ratio being $9.31\left(F_{1,72}=7.03\right.$ at the $1 \%$ level $)$.

After the Aminoplex 5 infusion ceased and was replaced by normal saline the secretion remained at a raised level for the next $30 \mathrm{~min}$. For the final $30 \mathrm{~min}$ of the test the acid output fell to near basal levels. It is also possible to show that the acid secretion $30 \mathrm{~min}$ after the onset and for the $\mathbf{3 0}$ min following Aminoplex 5 infusion was significantly greater than the basal first hour, the expected mean square ratio being $13.17\left(F_{1,72}=11.88\right.$ at the $0 \cdot 1 \%$ level $)$.

\section{Blood glucose}

Blood glucose levels were measured in subject 3 during the first, fifth and ninth 15-min period and in subject 4 during the fifth and ninth 15-min period. The values in $\mathrm{mg} / 100 \mathrm{ml}$ blood were 135,140 and 128 for subject 3 , and 79 and 76 for subject 4 respectively. These levels do not indicate significant hypoglycaemia during the Aminoplex 5 infusion.

\section{Serum gastrin}

Serum gastrin levels (Fig. 2), show no change by virtue of the Aminoplex infusion.

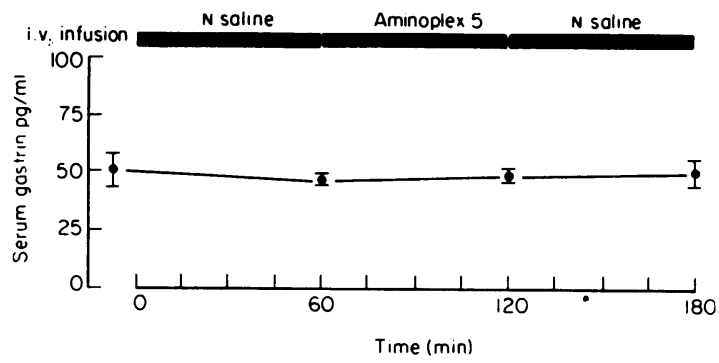

Fig. 2. The mean serum gastrin (s.e. mean) in $\mathrm{pg} / \mathrm{ml}$ of ten subjects.

\section{Discussion}

Aminoplex 5 which is used to provide the essential amino-acids, together with some carbohydrate, in patients who are unable to absorb food from the gastro-intestinal tract, contains ethanol which is known to stimulate gastric secretion when injected intravenously, Hirschowitz et al. (1956). L-leucine can produce hypoglycaemia (Marks and Rose, 1965) when injected intravenously and this constitutes a second possible source of gastric stimulation.

There was a small increase in the mean level of gastric acid secretion, as a result of the intravenous Aminoplex 5, which commenced $30 \mathrm{~min}$ after the infusion and continued for $\mathbf{3 0} \mathrm{min}$ after the infusion was stopped. This increase of secretion is statistically significant but is far below that found in normal males secreting maximally under the influence of either histamine, betazole or pentagastrin (Baron, 1972). There is no alteration in the plasma concentration of either glucose or gastrin and this suggests therefore that the stimulus to secretion is the ethanol which may be acting directly on the parietal cells.

Subjects who require intravenous amino-acids may therefore be given this preparation for at least $1 \mathrm{hr}$ without fear of gastric hypersecretion and presumably with little risk of the formation of a gastric or duodenal erosion.

\section{Acknowledgments}

Our thanks are due to the subjects who participated, to Geistlich Limited for their generous help, to Dr P. Hansell for preparation of the illustrations, to James $M$. Coles for statistical advice and to Miss Althea Pudney for typing the script. The gastrin assay was established with the help of a generous grant from the Westminster Hospital Governor's discretionary fund. 


\section{References}

Baron, J.H. (1972) Gastric function tests. In: Chronic Duodenal Ulcer (Ed. by C. Wastell), p. 93. Butterworths: London.

Hansky, J. \& CAIN, M.D. (1969) Radio immuno-assay of gastrin in human serum. Lancet, ii, 1388.
Hirschowitz, B.I., Pollard, M.H., Hartwell, S.W. \& LoNDON, J. (1956) The action of ethyl alcohol on gastric acid secretion. Gastroenterology, 30, 244.

MARKS, V. \& RoSE, F.C. (1965) Acquired sensitivity. In: Hypoglycaemia, p. 223-4. Blackwell Scientific Publications: Oxford. 